Cuadernos de $\mathrm{H}$ ideas

ISSN: 2313-9048

cuadernosdehideas@perio.unlp.edu.ar

Universidad Nacional de La Plata

Argentina

Reseña a Adriana María Valobra. Ciudadanía política de las mujeres en Argentina, Ciudad Autónoma de Buenos Aires, Grupo Editor Universitario / Eudem, 2018, 110 páginas

\author{
Canillo, Nuria \\ Reseña a Adriana María Valobra. Ciudadanía política de las mujeres en Argentina, Ciudad Autónoma de Buenos \\ Aires, Grupo Editor Universitario / Eudem, 2018, 110 páginas \\ Cuadernos de $\mathrm{H}$ ideas, vol. 13, núm. 13, e023, 2019 \\ Universidad Nacional de La Plata, Argentina \\ DOI: https://doi.org/10.24215/23139048e023
}

Esta obra está bajo una Licencia Creative Commons Atribución-NoComercial-Compartirlgual 4.0 Internacional. 
Reseñas bibliográficas

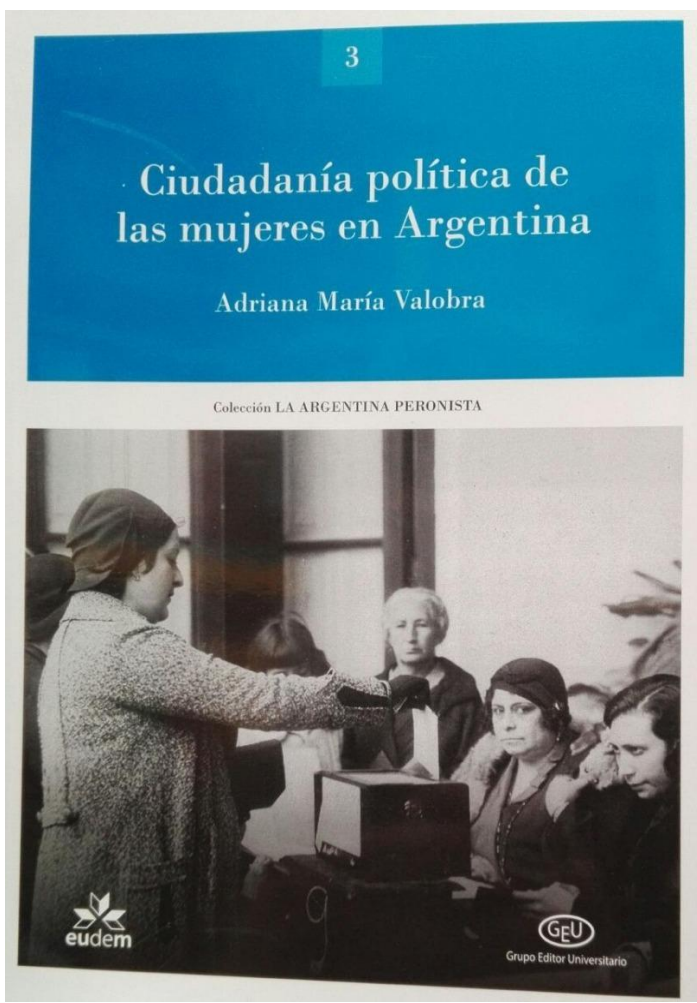

\section{Reseña a Adriana María Valobra. Ciudadanía politica de las mujeres en Argentina, Ciudad Autónoma de Buenos Aires, Grupo Editor Universitario / Eudem, 2018, 110 páginas}

Review to Adriana María Valobra. Ciudadanía política de las mujeres en Argentina, Ciudad Autónoma de Buenos Aires, Grupo Editor Universitario / Eudem, 2018, 110 pages

Nuria Canillo nuriacanillo@gmail.com Universidad Nacional de Mar del Plata, Argentina
Recibido: 05/05/2019 Aceptado: 27/05/2019 Publicado: 13/09/2019
En septiembre de 1947 fue sancionada en Argentina la ley de sufragio femenino. Así, 35 años después de la aprobación de la Ley Sáenz Peña, el derecho al voto era extendido a las mujeres. Sin embargo, esto no significó que pudieran ejercer con plenitud esta ciudadanía política recién adquirida, ni que lo hicieran en pie de igualdad con los varones. Es a partir de este hecho que Adriana Valobra se propone analizar, desde una perspectiva crítica y de género, dos dimensiones de la ciudadanía política de las mujeres: el ejercicio del sufragio y la representación parlamentaria.

Su libro forma parte de la colección La Argentina Peronista: politica, sindicalismo, cultura, la cual pretende dar a conocer los últimos avances de la investigación académica sobre el período. La colección tiene por objetivo ser un medio para la divulgación histórica y pretende acercarse al público en general interesado en la Historia. En este sentido, Ciudadanía politica de las mujeres..., por su extensión y por su escritura accesible, apunta a ser leído tanto por docentes y estudiantes universitarios, como por docentes de escuela media, militantes, activistas, sindicalistas y todos aquellos interesados en el tema. La obra, a su vez, es fruto de la necesidad de dar a conocer los resultados de las investigaciones en historia de las mujeres y con perspectiva de género de una forma sencilla pero no simplificada. No obstante, la autora persigue un objetivo más ambicioso: apunta a que la comprensión crítica de los procesos históricos afiance un tipo de conocimiento de carácter transformador. Es decir, desea que su libro se convierta en una herramienta para la construcción de una sociedad más equitativa en términos de género. 
Para dar comienzo al libro, Valobra introduce la problemática mediante el análisis de una nota publicada en el año 2017 por el diario $L a$ Nación, "Paridad de género: adiós al mérito". De acuerdo a los fines de lo que entendemos como divulgación histórica, la reflexión sobre el artículo funciona como un disparador. Por un lado, para involucrar a les lectores de entrada en el tema y, por el otro, para dar cuenta que somos resultado de ciertos procesos históricos que confluyen en nuestro presente. En esta primera aproximación, la autora da cuenta de la necesidad de sumergirse en el pasado para encontrar las raíces de aquella mirada binaria que excluye violentamente a las mujeres de la política y sitúa a los varones como referentes modélicos.

El libro está compuesto por cuatro capítulos que abordan los temas centrales de su investigación y culmina con un apartado final a modo de conclusión. El capítulo I "Los estudios de género y la historia de las mujeres” presenta un acercamiento al devenir de la bibliografía más relevante escrita en esta perspectiva y da cuenta del rol fundamental que ha tenido y tiene el movimiento feminista y LGTTBIQ+ al introducir en escena ciertos debates que son retomados por las Ciencias Sociales. Principalmente, presenta conceptos clave para entender de qué hablamos cuando decimos mujeres y género, los cuales resultan fundamentales para la comprensión de la obra. En este capítulo la autora se posiciona epistemológicamente frente a cómo la historia se ha encargado de entender a las mujeres. Según su análisis, la historia política se ha caracterizado por privilegiar a ciertos sujetos masculinos hegemónicos, aquellos llamados "grandes hombres" que realizaban los "grandes hechos", dejando de lado a quienes no encajaban en esta categoría. En contraposición, Valobra recupera las nociones de mujeres y género como puntos de vista para repensar la historia en general, cuya implementación requiere cambiar la interpretación de los procesos históricos tal como han sido concebidos hasta ahora.

El capítulo II se titula "Mapear las luchas por los derechos políticos de las mujeres" y trata sobre los precedentes en materia de participación política de las mujeres durante el siglo XIX y principios del XX. Recoge distintas historias de vida y experiencias de militancia en torno a la lucha por estos derechos. En este sentido, Valobra menciona que en algunas provincias se logró el voto femenino antes de la ley de 1947. Sin embargo, estas experiencias fueron fragmentarias en el territorio nacional y de carácter excepcional, a las cuales denomina "derechos políticos a retazos". A su vez, caracteriza el periodo en general como un momento en donde los derechos femeninos empezaron a ser debatidos públicamente tanto en organizaciones civiles y partidarias como en las Cámaras legislativas nacionales. Destaca el surgimiento y el desarrollo del movimiento sufragista, el cual tuvo una creciente tendencia universalista en la demanda por el derecho a voto de las mujeres. Además de hacer este recorrido histórico, analiza los modelos de identidad por medio de los cuales eran entendidas las mujeres en aquella época. De esta manera, da cuenta de cómo el pensamiento de las feministas-sufragistas concordaba 
o entraba en tensión con un discurso que Valobra denomina ideología de la domesticidad.

El capítulo III, "De leyes, legisladoras y dilemas en la participación: 1947-1955”, constituye el apartado central de la obra. Allí se aborda la conformación de la ciudadanía política de las mujeres y cómo éstas accedieron al voto a lo largo del decenio peronista. Para entender parte de este proceso, se recuperan las discusiones desarrolladas en torno a la presentación del proyecto de ley, las que estuvieron marcadas por distintas vertientes políticas. En el Senado, el peronismo, lejos de adoptar un discurso común sobre el proyecto de ley, se basó en distintas tradiciones para sostener este derecho, retomando, principalmente, las tradiciones de la iglesia y de las feministas sufragistas, mientras que sólo algunos pocos mencionaron a Evita y los tratados internacionales sobre el tema. Sin embargo, a pesar de la multiplicidad de debates alrededor de la ley, terminó primando una visión que se centró exclusivamente en los derechos políticos, dejando de lado los sociales y económicos. En este sentido, la autora destaca dos omisiones en el modo en el que los legisladores pensaron el voto de las mujeres. Por un lado, éstas no eran convocadas a votar en tanto ciudadanas y, por el otro, la ley se presentaba en términos de reparación hacia las mujeres. Es decir, las mujeres se transformaron en electoras pero no en ciudadanas, lo cual, si bien significó un avance, se convirtió en un cerco para una aprehensión más plena de sus derechos políticos. A esta situación Valobra la denomina "inclusión excluyente". De este modo, entiende que hubo una modernización excluyente, expulsiva de sujetos como las mujeres, quienes expresaron autonomías que el sistema no estaba dispuesto a permitir.

Otra variable que analiza el capítulo III es la intención del peronismo de peronizar la ley, de apropiársela despojándola de los atributos y las luchas legadas por la vieja tradición sufragista. En esta operación discursiva la figura de Evita fue central, quien planteó la politización del hogar, rompiendo con la idea del maternalismo político donde las mujeres trasladaban sus virtudes del espacio privado al público. Lo político/ partidario comenzó a atravesar la vida de las mujeres invitándolas a romper los límites entre dichos espacios. En este recorrido, la historiadora no se olvida de tomar en cuenta las experiencias de aquellas mujeres que lograron acceder a las Cámaras legislativas a partir de las elecciones de 1951. Estas mujeres, todas ellas pertenecientes al peronismo, tuvieron una función diferenciada al interior de dichas Cámaras. En este ámbito, los proyectos presentados mantenían una tendencia donde la figura de Evita era primordial. Para Valobra las mujeres actuaron como un sub-bloque sexualmente diferenciado, ya que de forma mayoritaria suscribieron a proyectos juntas.

El cuarto capítulo, bajo el título "Después de la ley de derechos políticos, ¿qué?", analiza brevemente el camino que atravesaron los derechos de las mujeres durante el período 1955 - 1976. Como sabemos, dicho período estuvo marcado fuertemente por la inestabilidad política y la alternancia entre gobiernos democráticos y dictatoriales. En el transcurrir de estos años, para la autora, las mujeres no lograron escapar 
de los mecanismos de control y castigo que instauraron cruelmente las dictaduras cívico-militares que sufrió nuestro país. Aunque señala que frente a estos contextos opresivos desarrollaron prácticas de resistencia. Durante este período, Valobra advierte que si bien las mujeres participaban en las elecciones en condiciones de igualdad jurídica, fueron relegadas a su vez en otros aspectos. Por ejemplo, a nivel político, la representación en el ámbito legislativo decayó. Pero al mismo tiempo, se fue dando un avance de las mujeres en los espacios de gestión del Estado. Este mayor involucramiento en la gestión fue posible por un fenómeno que se desarrolló en los años 60, especialmente con el incremento del índice de alfabetización de las mujeres. Esto les permitió ingresar al nivel secundario y aumentó su participación en la universidad. A pesar de éstos logros, éstas "revoluciones posibles" quedaron truncas. Primó una mirada tutelada sobre la participación de las mujeres, donde ésta debía ser controlada y orientada a ámbitos locales, promoviendo una mirada gradualista sobre los espacios que se adaptaban a la "sensibilidad femenina". La autora asocia este proceso a un proyecto de modernización del Estado, en pos de la seguridad y la protección social de las mujeres, que se construyó en fuerte vinculación con el mundo católico.

Por último, Ciudadanía politica de las mujeres... culmina con unas "Palabras finales" a modo conclusión pero también como reflexión sobre el derrotero de las luchas políticas de las mujeres en Argentina, dando cuenta de las nuevas formas de organización y movilización que ha desarrollado el feminismo en su recorrido más que centenario. Valobra señala que en el largo camino de adquisición de derechos políticos, en el que llegamos al 2018 con la Ley de Cupos y la Ley de Paridad de género, el avance de las mujeres en la representación políticoinstitucional no significó que éstas hayan asumido una mirada de género o que quieran romper con los estereotipos impuestos por la sociedad patriarcal. Por el contrario, advierte que en la mayoría de las mujeres presentes en los ámbitos legislativos y ejecutivos estos estereotipos se mantuvieron fuertemente arraigados a la ideología de la domesticidad. De esta manera, el libro pone de relieve que la adquisición de una ciudadanía política plena por parte de las mujeres es todavía una tarea pendiente, pero en construcción, y nos lleva a repensar en calidad de qué se pretende (o pretendemos) que las mujeres participemos dentro del ámbito institucional de la política. 